\title{
PERFIL EPIDEMIOLÓGICO DOS ÓBITOS POR AFOGAMENTO NO ESTADO DO TOCANTINS NO PERÍODO DE 2010 A 2014 EPIDEMIOLOGICAL PROFILE OF DROWNING DEATHS IN THE STATE OF TOCANTINS FROM 2010 TO 2014
}

\author{
Amanda de Lima Rodrigues ${ }^{1}$, Rebeca de Sousa Carvalho ${ }^{1}$, Pedro Manuel \\ Gonzales Cuellar².
}

\section{RESUMO}

Objetivo: Traçar o perfil epidemiológico dos óbitos por afogamento no estado do Tocantins no período de 2010 a 2014. Métodos: Análise dos dados obtidos através da plataforma online do Departamento de Informática do Sistema Único de Saúde (DataSus). Resultados: No período, foram registrados 337 óbitos por afogamento e submersão acidentais, desses, $82,19 \%$ eram do sexo masculino e $17,21 \%$, do sexo feminino. A faixa etária com maior número de casos foi de 20 a 29 anos com $17,51 \%$. Observou-se que 116 vítimas apresentavam entre 1 e 7 anos de estudo, 46, mais de 7 anos, 42, não tinham escolaridade e em 133 ocorrências (39,96\%) o dado foi ignorado. O mês com o maior número de ocorrências foi julho com 59 óbitos $(17,5 \%)$. Os municípios que registraram maior número de mortes foram Palmas (10,97\%), Araguaína (6,82\%) e Porto Nacional (6,23\%). Considerações finais: Os óbitos por afogamento implicam prejuízos econômicos diretos e indiretos, como aqueles empregados para o salvamento e secundários à perda de indivíduos jovens e potencialmente produtivos. Comprova-se então a importância do tema para saúde pública e a necessidade de planejamento e a alocação de recursos em ações de prevenção e para a proteção dos grupos de maior risco.

Palavras-chave: Afogamento, Mortalidade, Epidemiologia, Sistemas de informação.

\section{ACESSO LIVRE}

Citação: Rodrigues AL, Carvalho RS, Cuellar PMG (2017) Perfil epidemiológico dos óbitos por afogamento no estado do Tocantins no período de 2010 a 2014. Revista de Patologia do Tocantins, 4(3): 38.

Instituição: 'Acadêmico(a) de Medicina, Universidade Federal do Tocantins, Tocantins, Brasil; '2Docente, Médico Cirurgião, Universidade Federal do Tocantins, Tocantins, Brasil.

Autor correspondente: Amanda de Lima Rodrigues; amandadelima@outlook.com

Editor: Guedes V. R. Medicina, Universidade Federal do Tocantins, Brasil.

Publicado: 26 de setembro de 2017.

Direitos Autorais: (C) 2017 Rodrigues et al. Este é um artigo de acesso aberto que permite o uso, a distribuição e a reprodução sem restrições em qualquer meio, desde que o autor original e a fonte sejam creditados.

Conflito de interesses: os autores declararam que não existem conflitos de interesses.

\begin{abstract}
Objective: To describe the drowning death's epidemiological profile in the Brazilian State of Tocantins between 2010 and 2014. Methods: Data analysis from the information obtained through the Unified Health System's Information Technology Department (DataSus). Results: 337 deaths secondary to incidental drowning and submersion were reported, $82,19 \%$ of the victims were males and $17,21 \%$, females. The largest number of occurrences happened to subjects ranging from 20 to 29 years. 116 of the victims had attended school from 1 to 7 years, 46, more than 7 years, 42, never had gone to school and in 33 occurrences $(39,96 \%)$ this information was ignored. July registered most of the deaths $(17,5 \%)$. The highest number of deaths were reported in the cities of Palmas $(10,97 \%)$, Araguaína $(6,82 \%)$ e Porto Nacional $(6,23 \%)$. Final considerations: Drowning deaths imply direct and indirect economic losses, like those spent in water rescue and due to the destitution of young and potentially productive individuals from society. That proves the matter's relevance to Public health and the need of planning and allocating resources in prevention and protection of the most endangered groups.
\end{abstract}

Keywords: Drowning, Mortality, Epidemiology, Information systems. 


\section{INTRODUÇÃO}

Afogamento é definido como a asfixia durante imersão ou submersão causada pela entrada de líquido nas vias aéreas impedindo a ventilação e a troca gasosa alvéolocapilar (SZPILMAN, 2000). Afogamento por submersão ocorre quando a via aérea se encontra abaixo da superfície do líquido; afogamento por imersão ocorre quando é lançada quantidade de água suficiente sobre o rosto da vítima (SZPILMAN et al., 2012). Óbito por afogamento é definido quando a vítima é retirada do meio líquido sem possibilidades de ressuscitação (SEGUNDO; SAMPAIO, 2015).

Durante $\mathrm{o}$ processo de afogamento, a primeira reação da vítima é desvencilhar-se da coluna de líquido, cuspir ou engolir o líquido, seguido de apneia voluntária. Após, ocorrerá inspiração involuntária e o líquido na via aérea ocasionará reflexo de tosse ou laringoespasmos. Se esse processo não for interrompido, em geral em poucos minutos, a hipoxemia levará à perda de consciência e à parada cardíaca (SZPILMAN et al., 2012). Essa pequena janela de oportunidade para o salvamento justifica a importância de atuar na prevenção desses acidentes.

$\mathrm{O}$ afogamento e a submersão acidentais representam a 3 a causa mundial de morte por agravo não intencional e correspondem a $7 \%$ de todas as mortes por causas externas. Em qualquer região do mundo, este agravo figura entre as 10 causas de morte mais importantes na faixa etária de 1 a 24 anos (OMS, 2014a).

Os principais fatores de risco para afogamento são sexo masculino, idade menor que 14 anos, baixa renda, baixa escolaridade, crianças sem supervisão, efeitos do uso de álcool, superestimar capacidade de nado, doenças como arritmias cardíacas, epilepsia e autismo (SZPILMAN, 2005).

Anualmente, estima-se um total de 372.000 óbitos por afogamento, com o dobro de ocorrências para o sexo masculino e predomínio em países subdesenvolvidos, respondendo por $91 \%$ dos casos. O continente africano registra a maior taxa relativa de óbitos com 7,9 para 100.000 habitantes. A América Latina, por sua vez, apresenta a menor taxa entre as regiões mais pobres do globo - 3 óbitos para cada 100.000 (OMS, 2014a).

Segundo dados do Sistema de Informação sobre Mortalidade (SIM), no ano de 2014, o Brasil registrou 5304 óbitos por afogamento, com $62,7 \%$ do total nas regiões de maior densidade demográfica (IBGE, 2014), o sudeste e o nordeste brasileiros. Apesar de pequena participação absoluta nas ocorrências, a região norte registrou o maior risco, com razão de 4,96 óbitos para 100.000 habitantes, considerada elevada para o contexto nacional, que registra taxa de 2,61 óbitos para 100.000 no mesmo período (IBGE, 2014).

A ocorrência dos afogamentos varia conforme as condições geográficas de cada região, no entanto, maioria dos óbitos no mundo ocorre em água doce, incluindo banheiras, piscinas, lagos, canais e rios (SALOMEZ; VINCENT, 2004; SZPILMAN, 2015). De acordo com o Boletim da Sociedade Brasileira de Salvamento Aquático (SOBRASA) de 2015, 90\% dos óbitos por afogamento no Brasil ocorrem em águas naturais, $75 \%$ em água doce e $15 \%$ em praias oceânicas.

O Tocantins tem extensão de $286.706 \mathrm{~km}^{2}$, situa-se na Amazônia Legal e pertence à Região Norte do país. Limita- se com o Maranhão, Goiás, Piauí, Bahia, Mato Grosso e Pará (MINISTÉRIO DA EDUCAÇÃO, 2000). O clima do estado é predominantemente tropical, caracterizado por uma estação chuvosa (de outubro a abril) e outra seca (de maio a setembro). Sua hidrografia é delimitada a oeste pelo rio Araguaia e a leste pelo rio Tocantins. Ambos banham a maior parte do território, correndo de sul para norte, onde se encontram (BRITO et al., 2002). Durante o período de estiagem, ocorre a formação de bancos de areia nos rios do estado, dando origem às "praias fluviais" (SOUZA, 1999) cujas margens são empregadas para implantação de uma infraestrutura básica utilizada com finalidade turística e de lazer (BRITO, 2001).

O Produto Interno Bruto do Estado, em 2014, atingiu o valor de $R \$ 26,19$ bilhões, com maior participação do setor de serviços $(70,2 \%)$, seguido pela indústria $(15,8 \%)$ e pelo setor agropecuário (13,9\%) (CUNHA; EVANGELISTA; DIAS, 2014). Este panorama demonstra o crescimento da exploração de novas atividades econômicas no estado, que na época de sua criação, em 1988, tinha a economia vinculada à agropecuária (MINISTÉRIO DA EDUCAÇÃO, 2000).

De acordo com o censo de 2010, no Tocantins residiam 1.383.445 habitantes, distribuídos em 139 municípios, cujos principais são Palmas, Araguaína, Gurupi, Porto Nacional e Paraíso do Tocantins, reunindo cerca de $40 \%$ da população (IBGE, 2016).

Demonstrada a expressividade da região Norte em relação aos afogamentos de ocorrência em águas nacionais, faz-se necessário compreender o cenário local e a identificação de oportunidades para conter o problema. Desse modo, o presente estudo tem por objetivo traçar o perfil epidemiológico dos óbitos por afogamento no estado do Tocantins no período de 2010 a 2014, como base para intervenções e ações de prevenção relacionados ao tema.

\section{MATERIAL E MÉTODOS}

Foram realizados levantamento e análise de dados sobre as vítimas de óbito por afogamento e submersão acidentais de ocorrência no estado do Tocantins, referentes ao período de 2010 a 2014, a partir de dados do Sistema de Informação sobre Mortalidade (SIM), por intermédio da plataforma online do Departamento de Informática do Sistema Único de Saúde (DataSus).

Para a descrição do perfil de mortalidade, foi calculada a frequência de óbitos por ano e a frequência acumulada no período de estudo secundárias à classificação de "Afogamento e submersão acidentais", que inclui os códigos de W65 a W74 da 10a edição da Classificação Estatística Internacional de Doenças e Problemas Relacionados com a Saúde (CID-10) (OMS, 2007), ou seja, causas externas de morbidade e mortalidade nos seguintes agrupamentos:

\section{banheira;}

Afogamento e submersão durante banho em

Afogamento e submersão consecutiva a queda dentro de uma banheira;

Afogamento e submersão em piscina;

- Afogamento e submersão consequente a queda dentro de uma piscina; 
- Afogamento e submersão em águas naturais (córrego, curso d'água, lago, mar aberto e rio);

- Afogamento e submersão consequentes a queda dentro de águas naturais;

- Outros afogamentos e submersão especificados;

- Afogamento e submersão não especificados.

As causas de óbito abordadas no presente artigo excluem: afogamento e submersão devidos a acidente(s) de transporte (V01-V99); por água (V90.-, V92.-) e cataclisma (X34-X39).

Usou-se ainda, para fins de avaliação do risco de afogamento e comparação

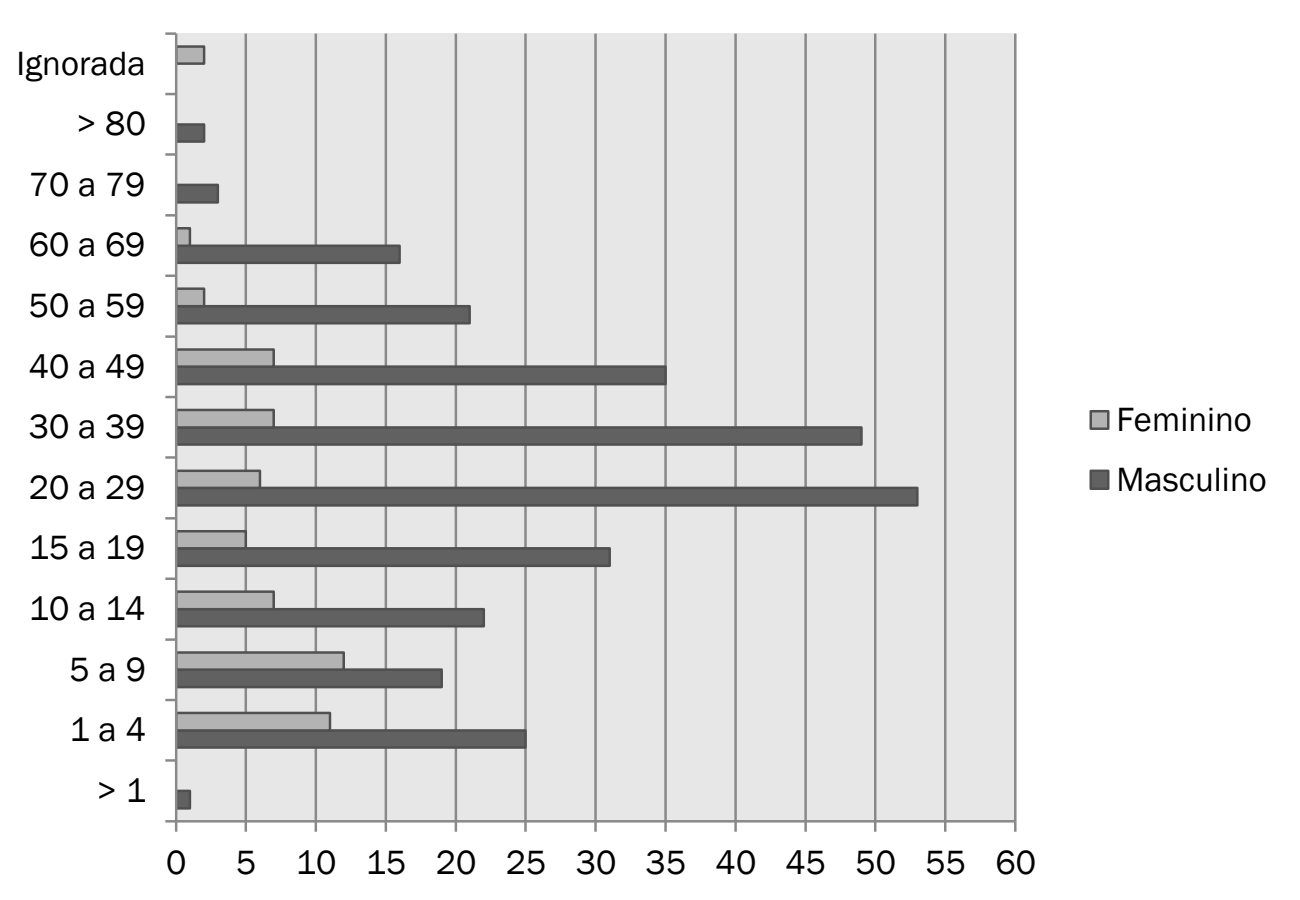
entre diferentes locais a razão entre a frequência absoluta de óbitos por afogamento, obtida através do DataSus, multiplicada por 100.000 e a projeção populacional (IBGE, 2014) para cada ano descrito, dessa maneira, as taxas sempre serão expressas "por 100 mil habitantes".

Dos óbitos decorrentes de afogamento e submersão acidentais, foram estudadas variáveis como sexo (masculino, feminino), faixa etária, escolaridade (zero, 1 a 3, 4 a 7, 8 a 11 e 12 ou mais anos de estudo), causa básica da morte - dividida neste trabalho entre as que se relacionavam a águas não naturais (W65 a W68), águas naturais (W69 e W70) e outros (W73 e W74), relação com acidente de trabalho e município da ocorrência.

\section{RESULTADOS}

De 2010 a 2014 foram registrados 337 óbitos por afogamento e submersão acidentais no estado do Tocantins. Desses, $82,19 \%$ eram do sexo masculino e $17,21 \%$, do sexo feminino. A faixa etária com maior número de casos foi de 20 a 29 anos com 17,51\% do total, seguida de 30 a 39 anos com $16,61 \%$. Os extremos de idade - menores de 1 ano e maiores de 80 anos - corresponderam ao menor número de ocorrências (Tabela 1). Enquanto a faixa etária masculina mais acometida encontra-se entre os 20 e 39 anos (36,82\%), entre as mulheres a maior incidência de óbitos ocorre no intervalo de 5 a 9 anos de idade (20,68\%) e 1 a 4 anos (18,96\%) (Figura 01).

Em 2010, ocorreram 61 óbitos por afogamento; 62, em 2011; 80, em 2012; 88, em 2013; 46, em 2014. O coeficiente de óbitos para cada 100 mil habitantes acompanhou essa proporção, com o maior risco registrado em $2013(5,95)$ (Figura 2). O mês com o maior número de ocorrências foi julho com 59 óbitos $(17,5 \%)$ no período analisado, seguido por abril com 39 (11,57\%). Novembro foi o mês com o menor número, respondendo por $5,64 \%$ dos óbitos nos cinco anos (Figura 03).

Figura 1. Idade e sexo das vítimas de óbitos por afogamento no Tocantins, 2010-2014.

Fonte: DATASUS. Informações de Saúde, Sistema de Informações sobre Mortalidade.

Em relação aos locais das ocorrências, os óbitos em águas não naturais contabilizaram $4,15 \%$ do total, dos quais $42,86 \%$ ocorreram na faixa etária de 1 a 4 anos, representando a faixa etária com maior número de casos. Entre os óbitos em águas naturais, a faixa etária com maior incidência se dava entre 30 e 39 anos (19,83\%) (Figura 4). Em $26,4 \%$ de todas ocorrências não havia especificação do Observou-se que 116 vítimas apresentavam entre 1 e 7 anos de estudo, 46, mais de 7 anos, 42, não tinham escolaridade e em 133 ocorrências (39,96\%) o DataSus não dispunha da informação. Entretanto, a partir dos dados disponíveis no sistema, verificou-se que a escolaridade predominante das vítimas nos acidentes em águas artificiais estava entre 1 e 3 anos de estudo $(21,43 \%)$, enquanto em águas naturais este intervalo correspondesse ao percentual de $28,21 \%$ dos casos (Figura 5 e Figura 6).

No período, os municípios que registraram maior número de mortes, foram Palmas (10,97\%), Araguaína (6,82\%) e Porto Nacional (6,23\%). Verificaram-se óbitos por afogamento em águas naturais em 78 municípios, porém somente 9 responderam pela categoria envolvendo piscinas e banheiras: Palmas, Araguaína, Colinas do Tocantins, Gurupi, Monte do Carmo, Pedro Afonso, Peixe, Porto Alegre do Tocantins e Taguatinga.

No âmbito dos acidentes em águas naturais, observou-se que em 26 municípios a quantidade de ocorrências reportadas superava o número de vítimas residentes na própria cidade. Por outro lado, em 15 municípios a quantidade de óbitos de moradores era maior do que as ocorrências locais, indicando que cidadãos originados ali foram a óbito em outra cidade. No total, registraram-se 234 ocorrências em águas naturais em todo o Tocantins e 229 óbitos de residentes no estado, que podem ou não ter ocorrido em solo tocantinense. 
Apenas $1,78 \%$ do total de óbitos relacionou-se a acidentes de trabalho, contra $64,89 \%$ associados a outros contextos (Tabela 1).

Figura 2. Coeficiente de óbitos por afogamento no Tocantins para cada 100.000 habitantes em paralelo com os dados brasileiros, 20102014.

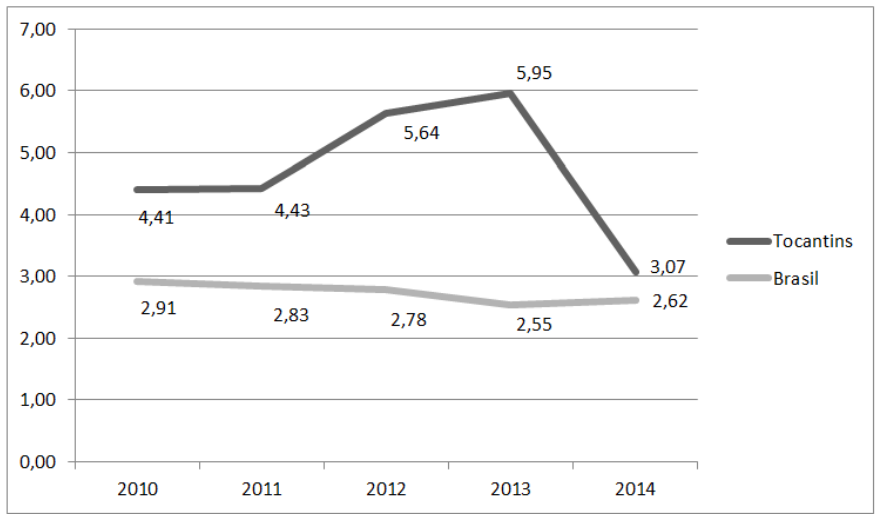

Fontes: DATASUS. Informações de Saúde, Sistema de Informações sobre Mortalidade; IBGE. Diretoria de Pesquisas, Coordenação de População e Indicadores Sociais.

Figura 3. Óbitos por afogamento no Tocantins distribuídos por mês, 2010-2014.

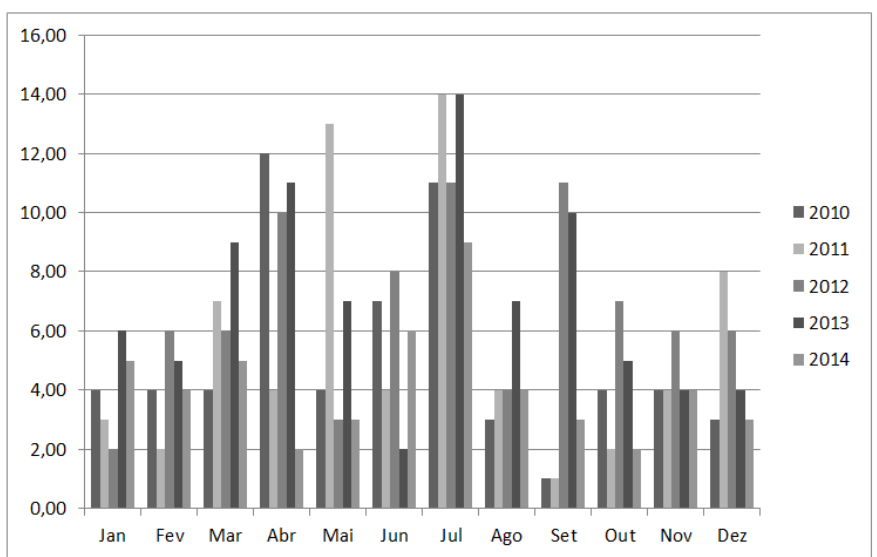

Fontes: DATASUS. Informações de Saúde, Sistema de Informações sobre Mortalidade.

Figura 4. Local de ocorrência e idade (em anos) das vítimas de óbitos por afogamento no Tocantins, em relação percentual ao valor absoluto de ocorrências em cada categoria, 2010-2014.

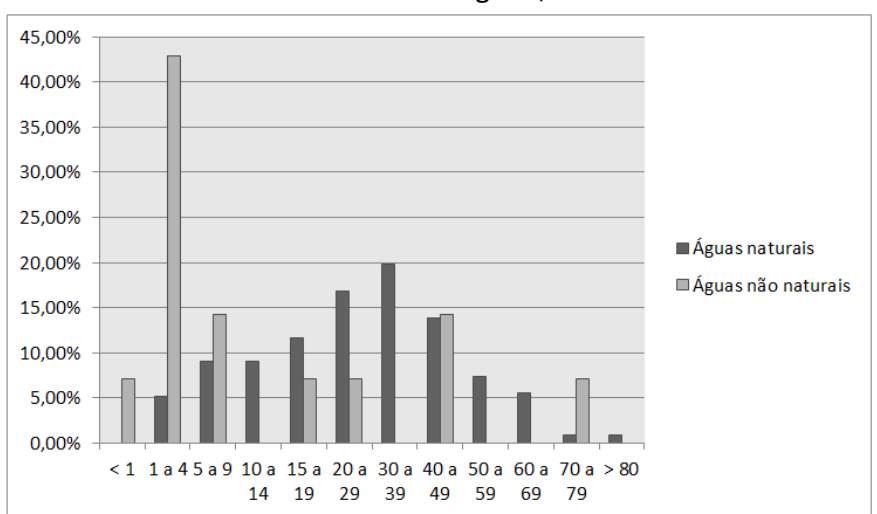

Fonte: DATASUS. Informações de Saúde, Sistema de Informações sobre Mortalidade.

Figura 5. Local de ocorrência e escolaridade (em anos de estudo) das vítimas de óbitos por afogamento no Tocantins, em relação percentual ao valor absoluto de ocorrências em cada categoria, 20102014.

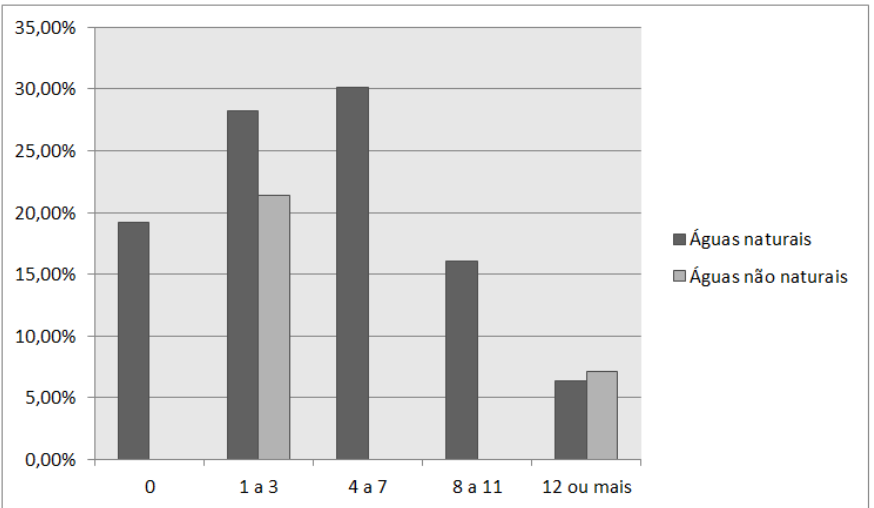

Fonte: DATASUS. Informações de Saúde, Sistema de Informações sobre Mortalidade.

Figura 6. Relação do local com a escolaridade (em anos de estudo) das vítimas de óbitos por afogamento no Tocantins, 2010-2014.

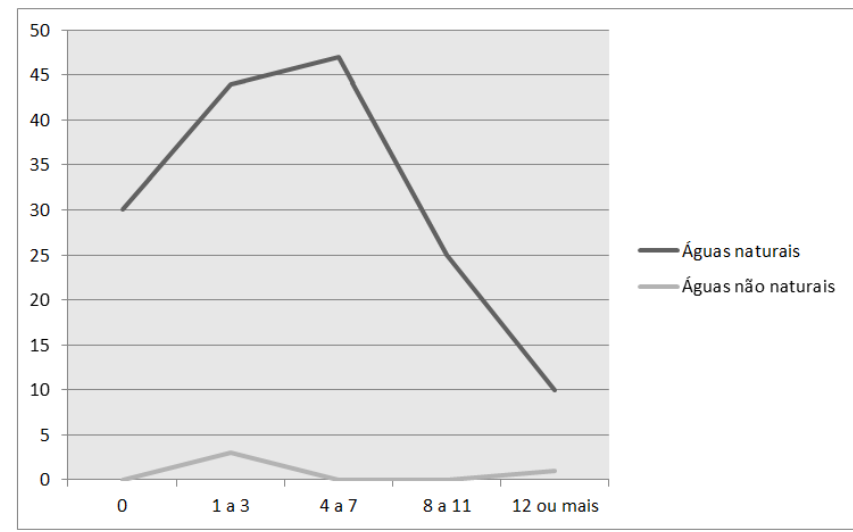

Fonte: DATASUS. Informações de Saúde, Sistema de Informações sobre Mortalidade.

\section{DISCUSSÃO}

De acordo com os dados apresentados, $82,19 \%$ das vítimas eram do sexo masculino e $17,21 \%$ feminino, proporção de quase 5 homens para cada mulher, resultados que se correlacionam com os dados obtidos em estudos epidemiológicos levantados (JÚNIOR; TABOSA; VIANA, 2012; OLIVEIRA et al., 1998; SEGUNDO; SAMPAIO, 2015; SOBRINHO et al., 2015) e com a média nacional que é 6 para 1 (SZPILMAN et al., 2012). A média mundial em 2014 foi de 2 homens para cada mulher (OMS, 2014a). Este fato possivelmente está relacionado à característica masculina de se expor a situações de risco com maior frequência e ao uso de álcool. Em 2010, a média mundial de álcool em litros consumida pelos homens foi 2,38 o volume consumido pelas mulheres (OMS, 2014b). Enquanto os óbitos entre homens ocorreram majoritariamente entre indivíduos em idade economicamente ativa, entre as mulheres, o predomínio esteve na faixa etária até 9 anos. Esses achados acompanham a tendência dos demais óbitos por causas externas, em que há grande participação da população mais jovem e maior relevância dos anos de vida perdidos no prejuízo social e econômico ocasionados por essas mortes (IUNES, 1997; MATOS; MARTINS, 2013). 
Segundo Szpilman (2000), afogamento é a segunda causa de morte entre 1 e 14 anos, no Brasil, e primeira causa, nas mesmas condições, segundo a OMS (OMS, 2014a). No Brasil, a idade de maior ocorrência de óbitos é de 20 a 29 anos, corroborando os dados apresentados neste levantamento nos quais essa faixa etária correspondeu a $17,51 \%$ dos óbitos no período. A faixa de 1 a 4 anos, representou $10,68 \%$ do total de óbitos e correspondeu a $42,86 \%$ dos óbitos em águas não naturais. Esses dados estão de acordo com o estudo de Szpilman (2012) que mostra que a maior parte dos óbitos em piscinas ocorrem dentro dessa faixa etária. Segundo o autor, esses afogamentos ocorrem 2 vezes mais durante o uso em lazer do que em quedas acidentais, sendo as piscinas residenciais o local de $49 \%$ dos casos.

Tabela 1. Distribuição de óbitos por afogamento no SIM segundo sexo, faixa etária, escolaridade, categoria CID-10 e relação ocupacional das vítimas no estado do Tocantins, 2010-2014.

\begin{tabular}{|c|c|c|}
\hline \multirow{2}{*}{ Variáveis } & \multicolumn{2}{|c|}{ Óbitos $(n=337)$} \\
\hline & $\mathrm{n}$ & $\%$ \\
\hline \multicolumn{3}{|l|}{ Sexo } \\
\hline Masculino & 277 & $82,19 \%$ \\
\hline Feminino & 58 & $17,21 \%$ \\
\hline Ignorado & 2 & $0,59 \%$ \\
\hline \multicolumn{3}{|l|}{ Faixa etária (em anos) } \\
\hline$<1$ & 1 & $0,29 \%$ \\
\hline $1-4$ & 36 & $10,68 \%$ \\
\hline $5-9$ & 31 & $9,19 \%$ \\
\hline $10-14$ & 29 & $8,60 \%$ \\
\hline $15-19$ & 36 & $10,68 \%$ \\
\hline $20-29$ & 59 & $17,51 \%$ \\
\hline $30-39$ & 56 & $16,61 \%$ \\
\hline $40-49$ & 42 & $12,46 \%$ \\
\hline $50-59$ & 23 & $6,82 \%$ \\
\hline $60-69$ & 17 & $5,04 \%$ \\
\hline $70-79$ & 3 & $0,89 \%$ \\
\hline$>80$ & 2 & $0,59 \%$ \\
\hline Ignorado & 2 & $0,59 \%$ \\
\hline \multicolumn{3}{|l|}{ Escolaridade (em anos de estudo) } \\
\hline 0 & 42 & $12,46 \%$ \\
\hline $1-3$ & 55 & $16,32 \%$ \\
\hline $4-7$ & 61 & $18,1 \%$ \\
\hline $8-11$ & 34 & $10,08 \%$ \\
\hline 12 & 12 & $3,56 \%$ \\
\hline Ignorado & 133 & $39,46 \%$ \\
\hline \multicolumn{3}{|l|}{ Categoria do CID-10 } \\
\hline $\begin{array}{l}\text { Afogamento em águas não naturais (W65, } \\
\text { W66, W67, W68) }\end{array}$ & 14 & $4,15 \%$ \\
\hline $\begin{array}{l}\text { Afogamento em águas naturais (W69 e } \\
\text { W70) }\end{array}$ & 234 & $69,44 \%$ \\
\hline Outros (W73 e W74) & 89 & $26,41 \%$ \\
\hline \multicolumn{3}{|l|}{ Secundário a acidente ocupacional } \\
\hline Sim & 6 & $1,78 \%$ \\
\hline Não & 219 & $64,89 \%$ \\
\hline Ignorado & 112 & $33,23 \%$ \\
\hline
\end{tabular}

Fonte: DATASUS. Informações de Saúde, SIM.

O grande número de ocorrências na faixa etária pediátrica envolvendo piscinas e momentos de lazer alerta para a necessidade de educação principalmente dos pais em relação à prevenção de acidentes. As medidas que poderiam ser efetivas nessas condições são: ensinar crianças maiores de 3 anos a nadar (OLIVEIRA et al., 1998), supervisão constante enquanto crianças estiverem dentro ou próximas de fontes de água, desligar filtros durante uso da piscina, proteger o local com grades de segurança para que as crianças não tenham acesso sem supervisão.

Em relação à escolaridade, $34,42 \%$ das vítimas possuíam de 1 a 7 anos de escolaridade, dado similar a estudo realizado em Salvador - BA (OLIVEIRA et al., 1998). A baixa escolaridade está relacionada à maior taxa de óbitos, evidenciando a importância da educação para esse grupo, seja por evidenciar o maior risco às crianças, especialmente no contexto de águas não naturais (SZPILMAN, 2015), quanto por sugerir baixo nível socioeconômico. O reconhecimento dos grupos de risco de maior relevância na localidade estudada favorece o planejamento de ações educativas direcionadas para eles.

Dos dados levantados, observou-se percentual significativo de informações ignoradas para as variáveis escolaridade $(39,46 \%)$ e acidente de trabalho $(33,23 \%)$. A avaliação dos dados, identificação de problemas e criação de medidas de prevenção em saúde pública, dependem primariamente de informações coletadas e enviadas a bases de dados. Se as informações não forem completas, todo o trabalho subsequente é comprometido, por isso a importância da conscientização de todos os profissionais envolvidos da responsabilidade em coletar com qualidade e alimentar sistemas de informações. Estudo em Pernambuco sobre mortalidade por causas externas (MELO; ALVES; LIMA, 2015), questionou sobre a falta de dados e preenchimento incorreto de declarações de óbitos por parte dos profissionais de saúde e defendeu a necessidade de capacitação sobre o assunto para esses profissionais.

No período analisado, julho foi o mês com porcentagem mais alta de óbitos, $17,5 \%$, correspondendo ao esperado, pois é o período de alta temporada nas praias do estado. Diferente do observado em estudo de Salvador (SEGUNDO; SAMPAIO, 2015), onde o mês de janeiro apresentou o maior número de casos, no Tocantins a formação das praias ocorre nos meses de menor índice de chuvas, junho a agosto (MARCUZZO; ROMERO; CARDOSO, 2014), quando os rios perdem volume de água. No litoral, os meses correspondentes ao verão são os de maior movimento nas praias devido ao clima propício e ao período de férias escolares, contribuindo para o aumento dos afogamentos.

Segundo o Documento Referencial Turismo no Brasil que analisou a atividade de 2011 a 2014, os deslocamentos realizados no interior dos próprios estados respondem pela maior parte das viagens domésticas dos brasileiros em quase todas as Unidades da Federação. No ano de 2013, os fluxos intraestaduais corresponderam a $29,8 \%$ do total no Tocantins (BRASIL, 2014). De maneira indireta, isso é demonstrado pela predominância de população autóctone $(97,86 \%)$ entre as vítimas e pela distribuição balanceada de óbitos de residentes e não residentes nos diferentes municípios. Este dado é importante porque evidencia que há oportunidade de realização de ações de prevenção ao longo de todo o ano, independente da temporada de praias, e que a responsabilidade por elas recai igualmente sobre as esferas municipal e estadual.

O coeficiente de óbitos para cada 100 mil habitantes variou de 4,41 em 2010 a 3,07 em 2014, sendo o maior em 2013 com 5,95. A variação mostrou uma tendência de 
crescimento nos 4 primeiros anos e queda acentuada no último ano analisado, dados que se mostraram na contramão do Brasil, onde a tendência foi de queda nos 4 primeiros anos e aumento no último. Em estudo realizado por Szpilman (SZPILMAN et al., 2012), todos os estados brasileiros apresentaram redução dos óbitos por afogamento na comparação dos períodos de 1998 a 2004 e 2005 a 2012, exceto o Tocantins. Além disso, a região norte apresentou o maior risco de óbito por afogamento e a sudeste o menor (SZPILMAN et al., 2012).

Os municípios com maior número de casos foram, respectivamente, Palmas, Araguaína e Porto Nacional. Essas cidades estão entre as 4 mais populosas do estado e apresentam características hidrográficas favoráveis a esse tipo de ocorrência.

\section{CONSIDERAÇÕES FINAIS}

Em vista do panorama apresentado, observa-se que o Tocantins é um estado com aspectos geográficos e sócio demográficos que favorecem o afogamento, na ausência de intervenções adequadas. Este problema implica prejuízos econômicos diretos e indiretos, na medida em que demanda gastos imediatos, como aqueles empregados para o salvamento, e representa a perda de indivíduos jovens e potencialmente produtivos. Comprova-se assim que a incidência de óbitos por afogamentos no estado constitui importante problema de Saúde Pública e demanda atenção dos gestores públicos, para o planejamento e a alocação de recursos em ações de prevenção e para a proteção dos grupos de maior risco.

\section{REFERÊNCIAS BIBLIOGRÁFICAS}

1. BRASIL. Turismo no Brasil 2011-2014. Disponível em: <https://www.portalbrasil.net/downloads/TurismoBrasil_Referen cial_2011_2014_Mtur.pdf>. Acesso em: 18 maio. 2017.

2. BRITO, E. R. Avaliação qualitativa de impactos ambientais decorrentes do empreendimento denominado "praias fluviais" no estado de Tocantins. [s.l.] Universidade Federal de Viçosa, 2001.

3. BRITO, E. R. et al. Perfil ambiental do empreendimento denominado de "praias fluviais", Estado do Tocantins. Rev. Árvore, v. 26, n. 3, p. 349-355, 2002.

4. CUNHA, G. P.; EVAngelistA, G. A.; DIAS, K. A. Produto interno bruto do estado do Tocantins 2014. Disponível em: $<$ https://central3.to.gov.br/arquivo/315536/>. Acesso em: 12 maio. 2017.

5. IBGE. População residente enviada ao Tribunal de Contas da União Brasil, Grandes Regiões e Unidades da Federação - 20012014. Disponível em: <ftp://ftp.ibge.gov.br/Estimativas_de_Populacao/Estimativas_20 14/serie_2001_2014_TCU.pdf >. Acesso em: 18 maio. 2017.

6. IBGE. Mapas e municípios. [s.l: s.n.]. Disponível em: $<$ http://cidades.ibge.gov.br/download/mapa_e_municipios.php?! ang $=$ \&uf $=$ to $>$.

7. IUNES, R. F. III - Impacto econômico das causas externas no Brasil: um esforço de mensuração. Revista de Saude Publica, v. 31, p. 38-46, ago. 1997.

8. JÚNIOR, M. L. P.; TABOSA, E. M. C.; VIANA, M. C. C. Perfil clínico e epidemiológico de pacientes vítimas de afogamento no município de Fortaleza/CE. Revista de Saúde Pública de Santa Catarina, v. 5 , n. 1, p. 19-27, 2012.
9. MARCUZZO, F. F. N.; ROMERO, V.; CARDOSO, M. R. D. Tendência do número de dias de chuva no estado do Tocantins e a relação dos seus extremos com o índice oceânico Niño. Boletim de Geografia, v. 32, n. 1, p. 1-16, 2014.

10. MATOS, K. F.; MARTINS, C. B. G. Mortalidade por causas externas em crianças, adolescentes e jovens: uma revisão bibliográfica. REVISTA Espaço para a Saúde, v. 14, p. 82-93, dez. 2013.

11. MELO, G. B. T.; ALVES, S. V.; LIMA, M. L. C. Mortalidade por causas externas em Pernambuco, 2001-2003 e 2011-2013. Revista Brasileira de Enfermagem, v. 68, n. 5, p. 855-861, 2015.

12. MINISTÉRIO DA EDUCAÇÃO. Indicadores socioeconômicos. Disponível em: <http://portal.mec.gov.br/conaes-comissaonacional-de-avaliacao-da-educacao-superior/190-secretarias-

112877938/setec-1749372213/12592-tocantins>. Acesso em: 17 maio. 2017.

13. OLIVEIRA, I. M. et al. Mortalidade por afogamento no Município de Salvador, 1980 a 1994. Informe Epidemiológico do Sus, v. 7, n. 071, p. 25-33, 1998.

14. OMS. CID-10 Classificação Estatística Internacional de Doenças e Problemas Relacionados à Saúde. São Paulo: Edusp, 2007.

15. OMS. Global report on drowning: preventing a leading killer. Geneva: [s.n.]. Disponível em: <http://apps.who.int/iris/bitstream/10665/143893/1/978924156 4786_eng.pdf?ua $=1 \& u a=1>$.

16. OMS. Global status report on alcohol and health 2014Global status report on alcohol. Geneva: [s.n.]. Disponível em:

http://www.who.int/substance_abuse/publications/global_alcoh ol_report/en/>.

17. SALOMEZ, F.; VINCENT, J. Drowning: a review of epidemiology, pathophysiology, treatment and prevention. Resuscitation, v. 63, p. 261-268, 2004.

18. SEGUNDO, A. S. S.; SAMPAIO, M. C. Perfil epidemiológico dos afogamentos em praias de Salvador, Bahia, 2012. Epidemiologia e Serviços de Saúde, v. 24, n. 1, p. 31-38, 2015.

19. SOBRINHO, E. R. O. et al. Perfil das ocorrências de vítimas afogadas atendidas por um serviço de atendimento móvel de urgência. Revista Saúde, v. 9, p. 46-55, 2015.

20. SOUZA, P. A. Análise e avaliação de impactos ambientais decorrentes da Praia da Graciosa, Palmas-TO.PalmasUNITINS, , 1999.

21. SZPILMAN, D. Afogamento. Revista Brasileira de Medicina do Esporte, v. 6, n. 4, p. 131-144, 2000.

22. SZPILMAN, D. Afogamento na infância: epidemiologia, tratamento e prevenção. Revista Paulista de Pediatria, v. 23, n. 3, p. 142-153, 2005.

23. SZPILMAN, D. et al. Drowning. New England Journal of Medicine, v. 366, n. 22, p. 2102-2110, 2012.

24. SZPILMAN, D. Afogamentos. [s.l: s.n.]. Disponível em: <http://www.sobrasa.org/new_sobrasa/arquivos/baixar/AFOGA MENTOS_Boletim_Brasil_2015.pdf>. 